\title{
CAMbio POLÍTICO-RELIGIOSO EN UNA LOCALIDAD tojolabal del municipio de Las Margaritas, Chiapas
}

\author{
José Luis Escalona Victoria
}

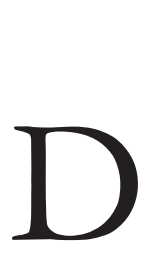
flictos que han derivado en expulsiones y enfrentamientos violentos. En este trabajo se explora una línea de análisis sobre el conflicto religioso en Chiapas, a partir de un acercamiento etnográfico a una localidad rural del municipio de Las Margaritas. En ella conviven miembros de distintas iglesias, a pesar de haber vivido un enfrentamiento y amenaza de expulsión en 1985 y de las experiencias cercanas de conflicto y expulsión que han ocurrido en poblados vecinos. No se propone que el caso represente ejemplo de una población que superó de manera definitiva el conflicto. Por el contrario, se propone que hay condiciones de diferenciación social muy semejantes en los pueblos de la zona que influyen en la dinámica del conflicto actual; pero también, que se producen distintas formas de manejar las diferencias y el conflicto en cada caso particular.

\section{Dos regiones indígenas de Chiapas al finalizar el siglo $\mathrm{xx}$}

Chiapas se encuentra en una de las zonas más importantes de cambio religioso en México: la frontera sur mexicana. Esta zona ha sido estudiada por el incremento importante de religiones no católicas desde los años ochenta del siglo xx (Rivera 2001a y 2001b, Rivera, García et al. en prensa). Por otro lado, es también una importante región de conflictos y de expulsión de población por diferencias religiosas. Los municipios con mayor número de casos de expulsión en el estado de Chiapas son San Juan Chamula y Las Margaritas (Rivera, García, Lisbona y Sánchez en prensa). San Juan Chamula está localizado en las montañas altas, al centro del estado, y Las Margaritas hacia el sureste, en la frontera con Guatemala. Se trata de dos municipios de importante población indígena que enfrentan un crecimiento demográfico importante a pesar de las limitaciones del mercado laboral en el estado. En síntesis, se trata de poblaciones rurales con una crisis en la relación entre crecimiento de población y disponibilidad de tierras y recursos para una agricultura de temporal, con escasas alternativas de empleo. ${ }^{1}$ 
Sin embargo, ambas zonas también presentan diferencias en estos aspectos. La densidad de población, la proporción de población indígena y la disponibilidad de tierra y recursos para la agricultura de temporal son distintas. Según datos para la última década del siglo xx, la densidad de población en ge- neral y de población indígena es mayor en la zona montañosa central que en los valles de Las Margaritas. Viqueira identifica a estas regiones como las Montañas Mayas (que se extienden hacia el norte del estado) y la Selva Lacandona (en donde se localiza el municipio de Las Margaritas).

\begin{tabular}{|c|c|c|}
\hline Para 1990 & Las Montañas Mayas & La selva lacandona \\
\hline Densidad de población & $\begin{array}{c}\text { 69 habitantes por hectárea } \\
\text { (la más alta de Chiapas) }\end{array}$ & $\begin{array}{c}\text { Menos de } 40 \text { habitantes } \\
\text { por hectárea }\end{array}$ \\
\hline $\begin{array}{c}\text { Porcentaje de población indígena } \\
\text { Propiedad social y propiedades } \\
\text { menores a 5 has. }\end{array}$ & $82.82 \%$ & $70.58 \%$ \\
\hline $\begin{array}{c}\text { Propiedad privada } \\
\text { de más de 5 has. }\end{array}$ & Más de $77 \%$ & Más de $77 \% *$ \\
\hline $\begin{array}{c}\text { Población que gana menos de } 1 \\
\text { salario mínimo } 1 / 3 \text { de la superficie }\end{array}$ & Más de $75 \%$ & $\begin{array}{c}\text { Menos de } 1 / 10 \\
\text { de la superficie }\end{array}$ \\
\hline $\begin{array}{c}\text { Producción de maíz } \\
\text { por habitante }\end{array}$ & De 50 a $260 \mathrm{~kg}$ & Más de $75 \%$ \\
\hline
\end{tabular}

Fuente: Viqueira 2002: 75-108, 261-285. Cuadros 1 y 2; Mapas 2, 3, 4, 6, 10

* En la región tojolabal (las montañas tojolabales o "tojolabal higblands") se registra menos de 10\% de propiedad privada para 1992. Lo demás es ejidal, copropiedades y tierras ocupadas por campesinos sin legalizar. Fuente: Van der Haar 2001: 56.

Así, aunque las dos regiones plantean los mismos problemas relativos a la disponibilidad de recursos para la población creciente, la situación es más seria para algunas poblaciones de la región de las montañas mayas.

\section{Tendencias demográficas en la región tojolabal}

Los tojolabales se encuentran principalmente en dos municipios de la región selva lacandona (Las Margaritas y Altamirano) y, en mucho menor número, en otros tres municipios de la región Llanos de Comitán (Comitán, La Trinitaria y La Independencia). En este trabajo me voy a referir en particular a un área rural localizada en torno a la cabecera municipal de Las Margaritas. Desde el reparto agrario ha habido un importante incremento de la población en la llamada zona tojolabal. Revisemos algunos ejemplos de poblaciones. 


\begin{tabular}{|c|c|c|c|c|c|c|c|c|c|}
\hline Año & $\begin{array}{c}\text { Nuevo } \\
\text { México }\end{array}$ & Bajacu & $\begin{array}{c}\text { Justo Sierra } \\
\text { (San Francisco) }\end{array}$ & Saltillo & Jalisco & $\begin{array}{c}\text { Plan de } \\
\text { Ayala }\end{array}$ & $\begin{array}{c}\text { Veinte de } \\
\text { Noviembre }\end{array}$ & Veracruz & San Mateo \\
\hline 1900 & & 347 & & & & & & & \\
\hline 1910 & & 312 & & & & & & & 137 \\
\hline 1921 & & 307 & & & & & & & 332 \\
\hline 1930 & & 280 & & & & & & & 279 \\
\hline 1940 & & 398 & & 350 & 364 & 434 & & 227 & 277 \\
\hline 1950 & 171 & 446 & 218 & 224 & 402 & 654 & 459 & 311 & 102 \\
\hline 1960 & 291 & 522 & 300 & 408 & 593 & 900 & 742 & 469 & 120 \\
\hline 1970 & 316 & 616 & 358 & 459 & 653 & 1039 & 914 & 557 & 23 \\
\hline 1980 & 396 & 782 & 557 & 659 & 777 & 1036 & 1100 & 656 & 45 \\
\hline 1990 & 605 & 1084 & 938 & 948 & 1186 & 1718 & 1486 & 800 & 27 \\
\hline 2000 & 570 & 1443 & 1109 & 1026 & 1648 & 2171 & 1828 & 1018 & 40 \\
\hline
\end{tabular}

El cambio de color en las columnas indica el momento en que la propiedad dejó de ser una finca y se convirtió en colonia agrícola o la propiedad está registrada como "indefinida".

Fuente: INEGI “Archivo histórico de localidades”. http://mapserver.inegi.gob.mx $/$ dsist $/$ ahl2003 $/$ index.html?c=424

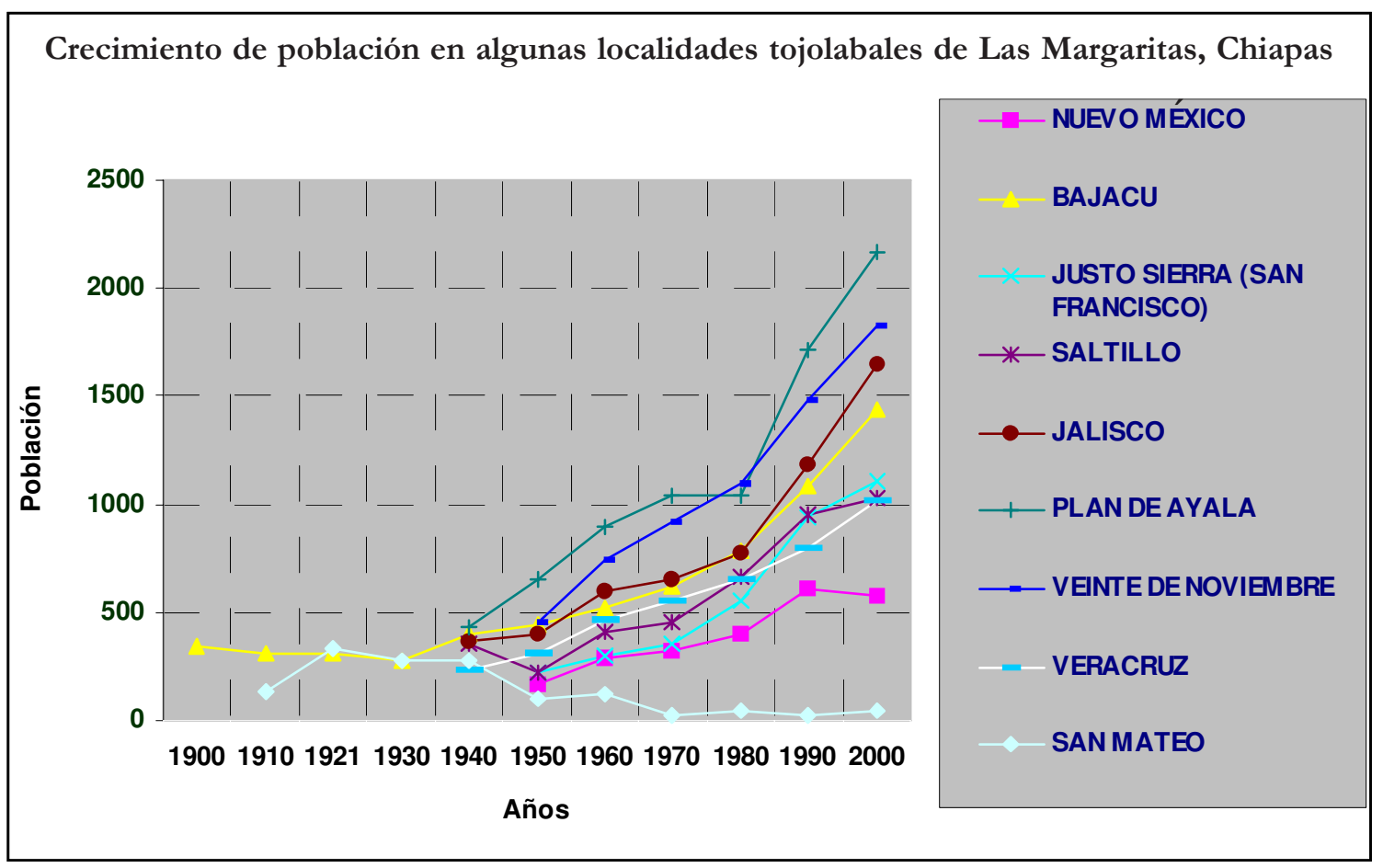


En todos estos casos se trata de poblaciones en donde se han registrado conflictos religiosos en las últimas dos décadas.

Sin embargo, la densidad de población no es tan alta como en los Altos de Chiapas. Además, la concentra- ción de población en el territorio también es muy baja. Según el censo de 2000 la mayor parte de los asentamientos es de menos de 2000 habitantes. De 348 asentamientos, sólo 2 son de más de 2000 habitantes.

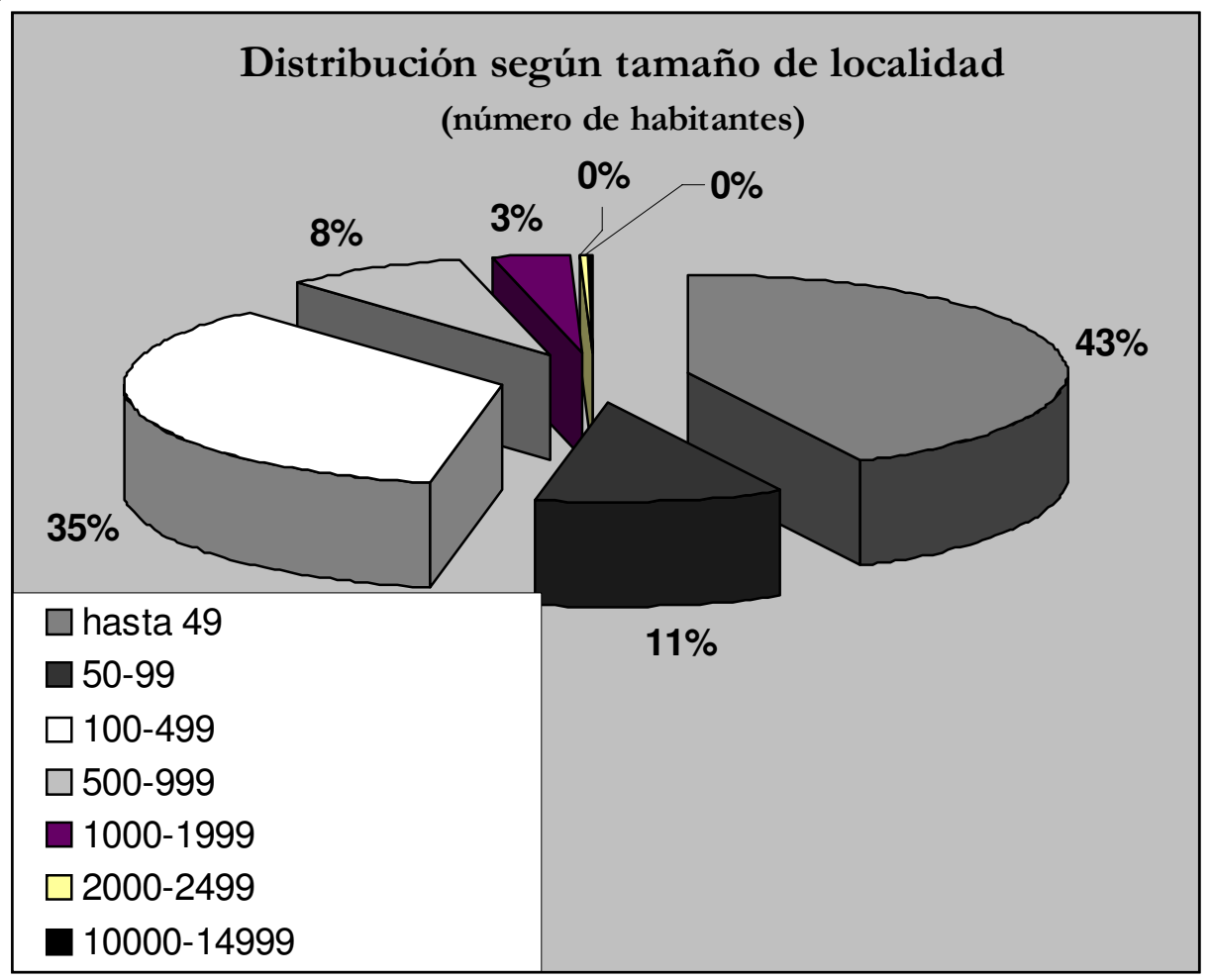

Fuente: Censo de población y vivienda 2000. INEGI

La producción de maíz es mayor que en los Altos de Chiapas, lo mismo que el número de cabezas de ganado por hectárea.

A pesar de la no tan alta densidad de población (en comparación con los Altos de Chiapas) algunos de los pueblos de la región se han convertido en expulsores de población, para la apertura de nuevas tierras, por la búsqueda de trabajo o por la expulsión de habitantes por diferencias religiosas y políticas. Pero eso no empezó en la última década. A lo largo de la segunda mitad del siglo Xx sus habitantes han colonizado las tierras de la selva al oriente del estado, en la frontera con Guatemala. Más recientemente, en los años ochenta, muchos pobladores han migrado a otras ciudades o hacia Estados Unidos, en busca de trabajo.

Al mismo tiempo, otros factores han influido en la expulsión de población en las últimas dos décadas del siglo xx. En este periodo los habitantes de los valles que 
se forman alrededor de la cabecera municipal han experimentado cambios importantes en las formas de producción de milpa, incrementándose el uso de agroquímicos que abaratan la producción, aunque requieren de menos mano de obra y a la larga generan dependencia hacia los insumos agrícolas comerciales. De esta forma, muchos trabajadores jóvenes salen a ganar dinero a otras regiones, mientras que la producción de milpa requiere cada vez más de gastos en pesticidas y fertilizantes.

Por ello, se observa que en estos municipios ha habido un crecimiento demográfico menor al estatal y al nacional en la última década del siglo xx, después de la década de los ochenta en donde se dio un crecimiento demográfico significativo.

\begin{tabular}{|c|c|c|c|}
\hline $\begin{array}{c}\text { Población total por } \\
\text { Municipio }\end{array}$ & $\mathbf{1 9 9 0}$ & $\mathbf{2 0 0 0}$ & $\begin{array}{c}\text { Tasa de crecimiento } \\
\text { anual }\end{array}$ \\
\hline Las Margaritas* & 86586 & 97560 & 1.20 \\
\hline Altamirano & 17026 & 21948 & 2.57 \\
\hline La Independencia & 27073 & 32245 & 1.76 \\
\hline Comitán & 78896 & 105210 & 2.92 \\
\hline La Trinitaria & 57975 & 59686 & 0.29 \\
\hline Total subregión & 267556 & 316649 & 1.70 \\
\hline Total estatal & 3210496 & 3920892 & 2.02 \\
\hline Total Nacional & $81,249,645$ & $97,483,412$ & 1.84 \\
\hline
\end{tabular}

*Incluye el nuevo municipio de Maravilla Tenejapa en 2000

Al parecer el crecimiento demográfico (bajo condiciones de agricultura milpera en las circunstancias descritas, además de las escasas alternativas para la agricultura y para generar empleo) ha llegado a un límite. El estudio de estos casos puede arrojar información interesante sobre la relación entre la diferenciación social, por un lado, y la diferenciación político religiosa, por el otro. Se requerirá de un análisis más profundo de datos sobre densidad de población y alternativas económicas para analizar qué importancia juegan estos elementos en los conflictos. Esa es una de las líneas de trabajo que se examinan en el presente documento. ${ }^{2}$ Lo que a continuación se anota son algunas líneas de investigación derivadas del trabajo de campo en una de estas localidades donde ha habido una convivencia entre asociaciones religiosas distintas sin haber derivado en expulsiones. Sin embargo, al mismo tiempo se propone que la tierra y los recursos derivados ya no son el único elemento por el cual se presentan los conflictos. Por el contrario, existen otros espacios de lucha por recursos que han surgido en las últimas décadas del siglo XX, y que tienen que ver con la aparición de iglesias, partidos políticos y programas gubernamentales.

\section{Los otros recursos}

A partir de los años setenta del siglo xx muchas organizaciones sociales y religiosas llegaron a la zona y empezaron a tener una influencia importante en la vida de los habitantes de los ejidos tojolabales, que se extendían en tres regiones: la montaña (los pueblos que se extienden sobre la carretera entre la cabecera de Las Margaritas y la del municipio de Altamirano), la selva (en la parte oriente de ambos municipios) y los valles de Las Marga- 
ritas. En lo que sigue me referiré a lo ocurrido en una población de esta última zona.

Primeramente, después de un periodo de abandono de la región, la Iglesia católica buscó intensificar su presencia en estos pueblos, con un nuevo proyecto evangelizador, que incluía la formación de catequistas entre jóvenes hijos de campesinos. Al mismo tiempo el gobierno federal impulsó un programa de formación de promotores bilingües, quienes más tarde se convertirían en maestros de escuela en la región. Éstos aumentaron en número y crecieron hasta abarcar los seis grados de la primaria. Más adelante, llegaron las organizaciones sociales y políticas, como el Partido Socialista Unificado de México (que se integró al Partido de la Revolución Democrática a fines de los ochenta, después de las elecciones presidenciales de 1988) y la Central Independiente de Obreros Agrícolas y Campesinos, que empezó a tener presencia en Las Margaritas desde principios de los ochenta. Los asociados a esta organización desempeñaron un papel importante en las tomas de tierras de los años ochenta en la zona de los valles de Las Margaritas, pues algunas fincas conservaban parte de sus antiguas tierras manteniendo relaciones con los ejidos que se formaron décadas atrás con otras fracciones de estas propiedades. Igualmente, en esos años, empezó el trabajo de asociaciones religiosas no católicas. ${ }^{3}$

Aunque la adquisición de tierras para cultivo fue el elemento central en la organización y la movilización en esos años, hubo también un aumento creciente en la importancia de otros recursos, además de la tierra y de la lucha por su apropiación. Tal es el caso de la legalización misma de la tierra, la formación de líderes hábiles en el trato con políticos y burócratas, la lecto-escritura, y paulatinamente también los cargos públicos en el municipio y en el gobierno estatal, o en las iglesias. Los empleos permanentes y los contactos en las ciudades cercanas fueron también valorados por los habitantes de los pueblos pequeños. Lo mismo ocurrió con la educación escolarizada. Eso se puede registrar también ahora en las múltiples veces en que la gente pide al antropólogo su apoyo en un trámite ante el gobierno, o para conseguir un empleo en la ciudad.

Hay entonces también otras dimensiones del conflicto por recursos, que tiene que ver con las organizaciones, iglesias, partidos y oficinas gubernamentales y no gubernamentales. En este caso no se trata sólo de recursos económicos o de fuentes de trabajo, sino también de relaciones que pueden ser utilizadas para la movilización y la legitimación de liderazgos o de posiciones en los ámbitos de autoridad de la región. En ese contexto también se producen los llamados conflictos religiosos. Por ejemplo, no es raro ver que parte del conflicto religioso se desarrolle en torno a otros asuntos que no tienen que ver con la religión, como en los casos en que se prohibe a niños no católicos la asistencia a la escuela o en los que se excluye de programas gubernamentales a familias conversas. El conflicto religioso se presenta como una dimensión del conflicto solamente, o mejor dicho, el conflicto tiene múltiples dimensiones, una de las cuales tiene que ver con el cambio de adscripción religiosa. Revisemos el ejemplo de San Mateo Veracruz, una localidad tojolabal cercana a la cabecera municipal.

\section{Luchas por recursos y enfrentamiento en Veracruz en 1985}

San Mateo Veracruz es una población tojolabal con menos de 1200 habitantes; se localiza a 12 kilómetros al norte de la cabecera municipal y se accede a ella por un camino sin pavimento. En 1985 esta población vivió un enfrentamiento entre, por un lado, un grupo vinculado a la CIOAC-PSUM y a los catequistas de la Iglesia católica; y por el otro, entre un conjunto de familias dentro las cuales se encontraban algunas conversas a la iglesia Adventista. Para explicar un conflicto que se produjo en los ochenta es necesario considerar la larga lucha por recursos en esta población. 
Cómo en otros casos, la tierra de que dispone ha sido apropiada en un largo proceso. ${ }^{4}$ Primero se dio el reparto agrario de mediados del siglo xx; después la colonización de las áreas de selva tropical al oriente y de otras tierras en las montañas y la depresión central. Así, en el periodo ya referido, ha salido de este lugar población a formar por lo menos otras cuatro localidades: Santa Inés, al sur de la depresión central de Chiapas; Santa Margarita Agua Azul, en la selva; Candelaria, rumbo a Altamirano; y recientemente Liberación Social, en La Trinitaria. Por último, desde los ochenta, se produjeron dos importantes invasiones de tierra: la toma de una fracción de la finca San Mateo en 1985, y la invasión del resto de la finca y la casa en 1994, con el levantamiento zapatista. Sin embargo, no se separó el núcleo de pobladores como producto de estas dos invasiones. Por el contrario, conviven en un mismo poblado tres grupos de propietarios (del ejido original llamado Veracruz 1936 - de una fracción de terreno cerril conocido como Kixtulá - 1985- y de un pedazo de tierra de riego y la casa de la finca San Mateo -1994). Esta propiedad diferenciada de tierras ha sido la base de la diferenciación de grupos al interior del mismo pueblo. Sin embargo, otros elementos tuvieron también una importante influencia en la formación de grupos en el pueblo.

Desde los setenta los nuevos catequistas católicos habían empezado a impulsar la organización de la gente siguiendo un plan para una nueva evangelización. Más tarde, algunos jóvenes maestros indígenas (formados por el gobierno federal) y algunos catequistas se vincularon con la CIOAC (que entonces se extendía por la región) y promovieron la organización para obtener nuevas tierras, para una generación de hijos de ejidatarios sin tierra. Apoyados en el PSUM (que participó por primera vez en elecciones municipales en Las Margaritas en 1983) esta organización logró aglutinar a muchas familias en el pueblo.

Al mismo tiempo, estos grupos de jóvenes sin tierra dirigidos por catequistas y maestros bilingües cuestiona- ron a las autoridades ejidales y a una persona a la que los ejidatarios había comisionado las gestiones de la ampliación de tierras. Se les reclamaba su falta de capacidad para obtener tierras nuevas. Todo eso se conjugó con acusaciones en contra de algunas familias que habían decidido ingresar a una nueva religión: Adventista del Séptimo Día.

La expulsión, de la que amenazaron varias veces, se iba a producir en enero de 1985; sin embargo, los conversos y algunos aliados católicos (pero opuestos al grupo de la CIOAC) decidieron abandonar el pueblo antes de la confrontación. Se sabía de antemano que incluso personas de poblaciones vecinas (también de CIOAC) vendrían a apoyar en la expulsión. Así ocurrió, aunque ante la salida previa de los conversos sólo hubo agresiones contra algunos hombres que permanecieron en el poblado y contra las pertenencias de estas familias.

Sin embargo, las autoridades estatales y municipales apoyaron a los amenazados de expulsión, los ayudaron a volver a sus casas y les ofrecieron ayuda económica para reponer lo destruido (herramientas e insumos agrícolas comerciales, instrumentos de cocina y ropa); pusieron también a un grupo de policías asentado en el centro del poblado (el cual permaneció por varias semanas). Al mismo tiempo, algunos líderes del grupo opuesto fueron apresados. Tres meses después, los católicos de la CIOAC tomaron las tierras cerriles de San Mateo.

El conflicto no era entonces sólo un asunto de religiones, incluyó muchos otros aspectos: la lucha por la tierra, por el liderazgo en el pueblo y por las relaciones con el gobierno (unos pidiendo apoyo y otros confrontando). El hecho de que se hayan combinado estos elementos es quizá el origen de la diversidad religiosa y política posterior: la expulsión no se consumó totalmente y la toma de tierras inmediatamente después alivió en parte la presión por recursos y por liderazgo. Finalmente, el crecimiento del minifundio, la insuficiente producción para el autoabasto y las difi- 
cultades de la ganadería o de la producción mercantil (como el café) han influido en la caída del valor económico de la tierra, impulsando a la creciente migración laboral. La misma migración ha devaluado a su vez la tierra, cosa que se expresa en las dificultades de los adultos para convencer a sus hijos de quedarse a trabajar en la agricultura. En este trabajo se plantea como hipótesis que estos hechos iniciaban un proceso de descentralización y cambio en el manejo de los recursos y un cambio en el valor relativo de la tierra para las nuevas generaciones, todo lo cual, a la larga, reforzó la diversidad religiosa y política en esta localidad.

\section{El manejo del conflicto: la descentralización de los recursos y de las formas de asociación}

La descentralización del manejo de recursos colectivos ha sido un elemento central en el mantenimiento de la diversidad político religiosa en este pueblo después de 1985. Esta descentralización se puede evaluar a través de una institución: las cajas. Se trata de dinero, producto de actividades colectivas, de contribuciones y de multas, que se maneja a través de comités nombrados con objetivos muy específicos.

Antes de 1985 sólo había una caja, manejada por las autoridades (que incluían al comisariado ejidal y la agencia municipal, cuyos cargos principales eran ocupados sólo por ejidatarios). Los líderes religiosos también tenían una influencia en los asuntos públicos y manejaban las contribuciones obligatorias de la gente para la celebración de la fiesta del santo patrón (San Isidro) y de las peregrinaciones anuales a poblados en las afueras del área de los pueblos tojolabales.

Sin embargo, después del conflicto aparecieron distintas cajas. El ejido administraba sus gastos propios, de manera separada de los vecinos sin tierra ejidal (muchos de los cuales adquirieron parcelas en las tierras invadidas en 1985); lo mismo ocurría con el grupo que había ocu- pado los terrenos de la finca en el 85 y con el que invadió las restantes fracciones de terreno en 1994. La base de esta organización descentralizada en el pueblo se encuentra en la existencia de tres núcleos agrarios en el mismo pueblo.

Pero la descentralización no corresponde sólo con eso, sino también con el hecho de que el gobierno y las iglesias y partidos traten con asociaciones locales y no con una única autoridad. Los que fueron temporalmente expulsados, entre los que se encontraban algunos no católicos, por ejemplo, recibieron una ayuda económica especial después de la agresión. A partir de entonces sólo los católicos contribuían para las celebraciones religiosas. Por su parte, las autoridades locales manejaban dinero de las obras y servicios públicos creando comités separados por cada uno de ellos. La introducción de obras y servicios que servían para toda la población (camino, agua entubada, electricidad) creó un manejo separado de los mismos. Algo semejante ocurrió con servicios manejados por asociaciones en particular, como las camionetas de transporte local. Las camionetas que hacen la ruta entre el pueblo y la cabecera municipal son de asociaciones de algunos habitantes del pueblo (o de particulares) y tienen su administración propia. Se establecen incluso regulaciones para el uso y manejo de estos recursos que sólo afectan a los miembros de la organización en cuestión (por ejemplo, los de la CIOAC están obligados a ser católicos y a usar los servicios de la organización, bajo pena de multas o de exclusión). Otro ejemplo de ello es el de los molinos de nixtamal, de los cuales existen dos: uno de la CIOAC, otro de los priistas. Así, mientras que antes de 1985 existía sólo una caja, para 2001 existían aproximadamente 16 cajas (de mujeres, de garrapata, de bomba de agua, etc.) que manejan dinero por separado. Incluso se hace uso del dinero para préstamos con intereses altos, lo que genera ganancias para los socios o por lo menos bajan sus contribuciones para los gastos del comité encargado. 
Esto sería irrelevante si no se supiera que algunos conflictos y expulsiones en otros pueblos tienen que ver con las contribuciones monetarias o en trabajo para asuntos colectivos (como las fiestas) o con el uso y disfrute de servicios como la tierra y la escuela. Tengo información de casos en los cuales se habla de prohibición para los hijos de conversos de asistir a la escuela (como es el caso de la comunidad "20 de noviembre" durante un conflicto en el año 2000), la exclusión de las mujeres de recibir dinero de programas gubernamentales (ahora llamado "oportunidades"), la enajenación de tierras tras la expulsión, y la obligación de pago de gasto ritual y de participación obligatoria en fiestas que implican el consumo de alcohol.

Así, un elemento central en la convivencia entre distintas iglesias que se tiene en Veracruz puede tener su base en la separación en el manejo de los recursos (y la descentralización de la autoridad correspondiente), que se desarrolló con la separación en el manejo de bienes y servicios, y en la diversificación de opciones de asociación para la gestión de apoyos por parte de iglesias y organizaciones frente a instituciones gubernamentales.

\section{El manejo del conflicto: el cambio religioso y sus contradicciones}

Otro elemento de análisis es el curso de las transformaciones que acompañan la "conversión" religiosa. El pueblo de San Mateo Veracruz está habitado por los descendientes de los fundadores del ejido Veracuz, además de los miembros de la CIOAC que invadieron un área extensa de terreno cerril de la finca San Mateo en 1985, y los que ocuparon lo que quedaba de la finca, las tierras más fértiles y la casona, en 1994 (que fueron, paradójicamente, priistas).

También conviven miembros de distintas asociaciones religiosas: los católicos, que integran algunos aspectos de anteriores formas de religiosidad, los Adventistas del Séptimo Día y los miembros de la iglesia de Reno- vación en Cristo. A partir del reparto agrario, y después de un largo periodo de alejamiento de la Iglesia católica en el que distintos aspectos de la religión quedaron en manos de la gente (en particular de ciertos especialistas rituales como los alférez y rezadores), los promotores de la Iglesia católica empezaron a trabajar con la población local, bajo la dirección del obispo Samuel Ruiz, en asociación con los Maristas que tenían una sede en Comitán (la Kastalia). A diferencia de otras zonas, la traducción de la Biblia al tojolabal fue promovida por estos católicos en Comitán. En los setenta ellos empezaron a capacitar a jóvenes hijos de campesinos para que aprendieran a estudiar la Biblia, además de ofrecer cursos sobre otros temas y capacitación en oficios. Algunos de estos jóvenes también recibirían capacitación como promotores de educación bilingües. A principios de los ochenta se inició la labor de una familia de Adventistas del Séptimo Día, que tenía vínculos con habitantes de poblados ubicados en la selva (lugar de arribo de gente de muchos sitios del país y de Guatemala). Interesante es el hecho de que algunos jóvenes preparados por la Iglesia católica se unirían ulteriormente a la iglesia Adventista. Finalmente, un joven del pueblo que conocía personas de otras poblaciones de la selva inició la iglesia de Renovación en Cristo, poco después del conflicto que se dio en el pueblo en 1985. Así, las influencias religiosas llegaron al ejido Veracruz de distintos lugares, unas desde el obispado y la ciudad más cercanos; otras, desde las áreas rurales de reciente colonización.

Si hay un elemento en común en estas religiones es que todas ellas confrontaron algunos aspectos de la religiosidad previa. ${ }^{5}$ Muchos aspectos de la vida social (matrimonios, defunciones, nacimientos) y del ciclo festivo (peregrinaciones y fiestas patronales) estaban a cargo de los especialistas rituales de la región. Los alférez se hacían cargo de las imágenes y del templo, los rezadores y principales dirigían grandes peregrinaciones y fiestas en otras poblaciones. Esta religiosidad incluía (entre otras cosas) las ofrendas en flores, velas y dinero, y el consu- 
mo de alcohol aun dentro de los templos, así como la realización de ritos para sanar y proteger a las personas, los animales y las cosechas. Algunos especialistas eran buscados también como curanderos y en ciertos casos eran acusados de ser "brujos" de causar infortunios en la vida cotidiana, desastres en la milpa, enfermedad y muerte. La llegada de las nuevas religiones confrontó estas prácticas directamente.

En primer lugar, la Iglesia católica buscó reinsertar algunas de aquellas prácticas en las formas aceptables del rito católico, mientras que rechazaron otras (como la muerte por acusaciones de brujería). Las asociaciones no católicas promovieron el abandono de estas prácticas, de los templos e imágenes, del alcohol y de algunos otros alimentos y bebidas (como el café y el refresco de color negro, en el caso de los Adventistas); al mismo tiempo integraron las ceremonias de bautizo, matrimonio etc., dentro de moldes aceptables de la nueva doctrina. Sin embargo, en todos los casos hubo un aprendizaje de dos vías y se dio paso, por ejemplo, a combinaciones entre los nuevos ritos religiosos de matrimonio y la amonestación de los padres para los novios como se hacía antaño. ${ }^{6}$

En segundo lugar, promovieron la formación de nuevos especialistas que rendirían cuentas al sacerdote o a los pastores o maestros de las nuevas iglesias, aunque con una gran independencia en el manejo de los feligreses en este pueblo (poco visitado por jerarcas de las iglesias). Eso dio espacio en la vida religiosa a jóvenes con habilidades de lecto-escritura y de discurso que no tenían los especialistas rituales anteriores. Sin embargo, otra vez, el desplazamiento no fue total y algunas prácticas (como ciertas formas de curación, la celebración de las fiestas patronales y las peregrinaciones) siguieron requiriendo de los antiguos especialistas. En un pueblo vecino (donde sí ha habido expulsiones) se produjeron incluso combinaciones interesantes: catequistas que además asumían las tareas de curanderos (Ver: Gómez 1996). ${ }^{7}$
En tercer lugar, hubo también cambios en algunas prácticas de la vida cotidiana, como en la higiene y la salud. Las iglesias, por ejemplo, fomentaron la atención médica de las enfermedades, al grado que ya no hay parteras ni nacimientos con parteras en el ejido Veracruz. Los catequistas también introdujeron el uso de sillas, mesas, camas, trasteros y otros utensilios y muebles domésticos. Igualmente se formaron jóvenes en nuevos oficios, como la costura y rudimentos de enfermería (saber inyectar es muy apreciado). El vestido y el baño son también vigilados en algunas asociaciones religiosas. Pero nuevamente los cambios no desplazaron del todo algunas prácticas, como los curanderos para ciertos padecimientos, ni el consumo de alcohol como parte de rituales religiosos. Así, el cambio religioso implicó adaptaciones paulatinas entre, por un lado, los modelos éticos promovidos por las iglesias y, por el otro, las condiciones de la vida cotidiana previas y las expectativas actuales de la gente. Muchos cambios no fueron introducidos sólo por una iglesia en particular, sino que fueron producto de la labor de todas. Por ejemplo, el consumo de alcohol se redujo sensiblemente y en 2003 se decidió prohibir su producción y venta, así como su consumo en áreas públicas (argumentando que detrás de casos de delitos y agresiones que tiene que atender la autoridad local siempre estaba el alcohol).

\section{El manejo del conflicto: los intercambios que atraviesan las diferencias religiosas}

También juegan un papel importante algunos intercambios que se producen entre los habitantes, a pesar de sus diferentes filiaciones políticas y religiosas. Por ejemplo, el gobierno local se ha modificado de manera importante después de 1985. Se establecieron áreas de autoridad diferenciadas. Los asuntos que involucran a todos son manejados en una asamblea general, mientras que otros asuntos sólo implican a los miembros 
de alguna organización. El acceso a los cargos de autoridad no se ha restringido como antes (que excluía a los no ejidatarios de algunos cargos); también se ha experimentado con nuevos métodos de elección: desde la formación de dos planillas (de los grupos mayoritarios) y la elección por "volado", asignando a la planilla ganadora los cargos importantes y a la perdedora los cargos menores; hasta la votación directa por candidatos para puestos individuales (es decir, no por planillas sino por personas).

La escuela, por ejemplo, no está asociada con religión alguna. La primaria (fundada a mediados de los sesenta) y el jardín de niños (fundado a mediados de los noventa) son tenidos como obras comunes, la única restricción se aplica para padres que no quieran contribuir con labores que requiere la escuela o que no envíen a sus hijos a la escuela. En la vida cotidiana también hay otros aspectos importantes. Hay que considerar además que se trata de un pueblo pequeño, donde los lazos entre la gente son múltiples. Los grupos de amistad y parentesco atraviesan a veces la filiación política y religiosa.

La cosecha o tapisca de maíz se realiza en parte con el apoyo de los amigos y parientes, a cambio de apoyo semejante de vuelta. Ello además conlleva reuniones al final de la cosecha, donde hay comida y bebida como parte de la reciprocidad entre familias. He tenido oportunidad de estar en eventos como estos en los que las personas son de distintas filiaciones políticas y religiosas. En las reuniones he registrado detalles importantes como el no hacer obligatorio el alcohol, sustituyéndolo por refresco, lo cual aparece como una parte importante de los arreglos novedosos de la reciprocidad. Igual pasa en fiestas de matrimonio en las que las familias de los contrayentes son de distintas organizaciones (aunque estos acontecimientos implican otros asuntos de organización e interacción de autoridades que no se pueden reseñar aquí sin extender más la exposición de asunto central).

Otro buen ejemplo es el del llamado kojtakin. Se trata de la matanza de una res organizada por un grupo de personas asociadas voluntariamente, regularmente en día de muertos (aunque puede ocurrir en cualquier fecha). Se comparte el gasto y el trabajo entre los asociados y se establecen regulaciones para el reparto del producto. Durante los trabajos se comparte también alcohol o alguna bebida. Tuve la oportunidad también de estar en un kojtakin en el que participaron miembros de distintas iglesias y organizaciones sociales, y donde se respetó el rechazo al consumo de alcohol por parte de los que asílo exigían. En contraste, por ejemplo, durante una conversación con un habitante de otra población, localizada en las montañas, Bajuku, me relataron el caso de una familia que fue multada por hacer kojtakin con personas de otro pueblo y de otra filiación política.

En los rituales de muertos también se observan esos intercambios entre personas de diferentes religiones. Aunque muchas cosas han cambiado, los rituales de día de muertos reúnen a toda la gente en el panteón. Se adornan y limpian las tumbas a partir de ciertos principios de parentesco y se respetan las restricciones de consumo de alcohol.

\section{A manera de conclusión}

En pueblos como éstos las relaciones de parentesco, de amistad y algunas prácticas rituales atraviesan las diferencias religiosas o políticas y activan lealtades que podrían de algún modo frenar la confrontación. También, como en el caso de Tzintzuntzan, Michoacán, analizado por Cahn (2003), las conversiones se produjeron haciendo una reelaboración de la doctrina y de la ética promovida por las religiones a partir de las condiciones y las relaciones de la población. Pero eso no obedece sólo a ciertas pautas o normas establecidas, sino también a que la disponibilidad de medios de vida y trabajo, y su manejo, no están concentrados en unas cuantas autoridades, sino descentralizados en distintas asociaciones. Este fue el caso aquí analizado, donde después de un enfrentamiento en 1985 se desarrolló 
un manejo descentralizado de recursos. Incluso, a diferencia del caso referido en Michoacán (y de otros en Chiapas) aquí se estableció que los no católicos no tienen que contribuir a las fiestas católicas. Lo que se evalúa en este proyecto es si la mayor presión por los recursos y su mayor centralización influyen en la agudización de las diferencias y los conflictos, o dicho de otra manera, si la existencia de formas de asociación y de distribución descentralizada de la autoridad permiten no eliminar el conflicto sino ordenarlo de manera que no se plantee la expulsión como única salida. ${ }^{8}$

\section{Notas}

${ }^{1}$ Para un análisis más preciso de la situación actual de la propiedad de la tierra y el crecimiento del parvifundio en algunas regiones indígenas de Chiapas, ver Villafuerte et al. 1999.

${ }^{2}$ Para el análisis de los cambios en las últimas décadas en algunos municipios de los Altos de Chiapas, ver: Cancian 1992, Collier 1989, 1994, 1997, Collier y Lowery 1998, Robledo 198, Rus 1994, Rus y Collier 2002, Sonnleitner 2001, Tejera 1997, Viqueira y Sonnleitner 2000. Para el análisis de la situación de la propiedad y uso de la tierra, revisar Villafuerte et al. 1999. ${ }^{3}$ Mientras que en la montaña tojolabal fueron las uniones de ejidos, vinculadas a la Unión de Uniones de la selva, las que tuvieron mayor presencia, el zapatismo tuvo la suya entre las poblaciones de la selva (Ver Harvey 1994 y 1998, Legorreta 1998 y Leyva 1995, Mattiace 1998, 2001, 2002 a y b).

${ }^{4}$ Para mayores datos sobre el reparto agrario en la zona tojolabal ver Van Der Haar 2000 y 2001.

${ }^{5}$ Para profundizar en estos aspectos de la religión y la vida social, ver Adams 1988, Escalona 2001, Gómez 1995, 1996, 2000, 2002, Gómez y Pinto 1998, Gómez y Ruz 1992, Gómez, Ruz y Palazón 1999, y Guzmán 2001, Ruz 1983.

${ }^{6}$ Sobre le matrimonio tojolabal, ver Gómez 2002.

${ }^{7}$ En su estudio en Tzintzuntzan, Michoacán, Cahn habla también de cómo la población acepta las religiones pero no de una manera radical, como un elemento que permite a las iglesias extenderse y ser aceptadas por los conversos. En este sentido también es interesante la literatura que habla de las formas locales en que las poblaciones se apropian las instituciones políticas y religiosas (Aitken 1999, Gilbert y Nugent 1994, Nugent y Alonso 1994, Starn 1992 y 1997, y Wilson 1995).
${ }^{8}$ Estos planteamientos son presentados con mayor detalle en Escalona 2000, 2001, 2003, 2004.

\section{Bibliografía}

Adams, Walter Randolph, 1988, "Religious practices of southeastern Chiapas and Tzeltal-Tojolabal interaction", en Lyte Campbell, The linguistic of southeast Chiapas, México, Papers of the New World Archaeological Foundation, Brigham Young University, Provo, Utah. Núm. 50, pp. 183-198.

Aitken, Rob, 1999, Localizing politics. Cardenismo, the Mexican State and local Politics in Contemporary Michoacan. PhD. Thesis, Research School CNWS, The Netherlands: Leiden University. Cahn, Peter, 2003, All religious are good in Tzintzuntzan. Evangelicals in Catholic Mexico. The University of Texas Press. Cancian, Frank 1992, The decline of community in Zinacantan. Economy, public life and social stratification, 1960-1978. Stanford University Press.

Collier, George, 1989, "Estratificación indígena y cambio cultural en Zinacantan 1950-1987”, en MESOAMERICA. Guatemala: CIRMA, 18 (Matices de la historia): 427-440.

- 1994, "The new politics of exclusion: antecedents to the rebellion in Mexico". Dialectical Anthropology, Spring 1994, 13: 1-44. -, 1997, "Reaction and retrenchment in the highlands of Chiapas in the wake of the Zapatista rebellion", Journal of Latin American Anthropology 3(1): 14-31.

—, and Lowery Q. Elizabeth, 1998, Basta: tierra y rebelión en Chiapas. México: Universidad Autónoma de Chiapas, First Food Books.

Escalona, José Luis, 2000, “Comunidad: jerarquía y competencia. Examen a través de un pueblo contemporáneo", en Anuario, Instituto de Estudios Indígenas, Universidad Autónoma de Chiapas, vIII: 179-211.

—, 2001, "Pluralismo y mediaciones: imaginario sociopolítico en Chiapas", en Salvador Maldonado (ed). Dilemas del Estado Nacional. México: El Colegio de Michoacán, pp 55-75.

—, 2003, Etnografía del poder: representaciones y estrategias locales", en Anuario, Instituto de Estudios Indígenas, Universidad Autónoma de Chiapas, Ix 211-226.

—, 2004, Contemporary politics in rural Chiapas. An ethnographic approach to power. PhD. Thesis. The University of Manchester.

Gómez Hernández, Antonio 1995, “Los santos milagrosos aparecidos en poblaciones Tojolabales, en Anuario, Instituto 
de Estudios Indígenas, Universidad Autónoma de Chiapas, v: 73-82.

—, 1996, "El lu'uminal o espacio terrestre y sus moradores según los tojolabales. Los 'vivos' y los 'cabeza de piedra' en el espacio terrestre”, en Anuario, Instituto de Estudios Indígenas, Universidad Autónoma de Chiapas, vi: 53-64.

—, y Delmi Marcela Pinto, 1998, "Och Nichim a la Santísima Trinidad, en Anuario, Instituto de Estudios Indígenas, Universidad Autónoma de Chiapas, vII: 159-174.

—, 2000, "El encuentro de los padres eternos: la romería a la Santísima Trinidad en Zapaluta”, en Anuario, Instituto de Estudios Indígenas, Universidad Autónoma de Chiapas, VIII: 243-260.

—, 2002, El Ch'ak ab'al. Del baldío a la actualidad. México: Universidad Nacional Autónoma de México. (Colección Científica, número 7).

—, y Mario H. Ruz (eds), 1992. Memoria baldía. Los tojolabalesy las fincas. Testimonio. México: Universidad Nacional Autónoma de México.

—, Mario H. Ruz y Maria Rosa Palazón (eds), 1999, Palabras de nuestro corazón. Mitos, fábulas y cuentos maravillosos de la narrativa tojolabal. México: Universidad Nacional Autónoma de México, Universidad Autónoma de Chiapas (Colección de Literatura Indígena Bilingüe, 3).

Guzmán, Adelita, 2001, "Romería o K’uanel al Padre Eterno en Zapaluta”, en Revista Pueblos y Fronteras, México, PROIMMSE_UNAM, núm. 2, pp. 127-142.

Harvey, Neil, 1994, "Rebellion in Chiapas: Rural Reforms, Campesino Radicalism, and the limits to Salinismo", en The transformation of rural Mexico, number 5, pp 1-49. La Jolla, California: Centre for U. S. - Mexican Studies, University of California at San Diego.

- 1998, The Chiapas Rebellion. The struggle for land and democracy. Durham and London: Duke University Press.

Joseph, Gilbert M. y Daniel Nugent, 1994, 'Popular culture and state formation in Revolutionary Mexico", en Joseph, Gilbert M. y Daniel Nugent (eds) Everyday Forms of State Formation. Revolution and Negotiation of Rule in Mexico. Durham and London: Duke University Press. pp 2-23.

Legorreta, María del Carmen, 1998, Religión, Política y Guerrilla en Las Cañadas de la Selva Lacandona. México, Cal y Arena.

Leyva Xochitl, (1995), "Catequistas, misioneros y tradiciones en la Cañada”. En Juan Pedro Viqueira y Mario H. Ruz (editores). Chiapas: Los rumbos de otra historia. México, UnAM, CIESAS, CEMCA. pp. 375-406.
Mattiace, Shannan Lorraine, 1998, Peasant and Indian: political identity and Indian autonomy in Chiapas, Mexico. 1970-1996. PhD. Dissertation. Austin: The University of Texas in Austin. August 1998.

—, 2001, "Regional renegotiations of space. Tojolabal ethnic identity in Las Margaritas, Chiapas". Latin American Perspectives. Issue 117, Vol. 28 Núm. 2. March 2001: 73-97.

—, 2002a, "Renegociaciones regionales del espacio: identidad étnica Tojolabal en Las Margaritas, Chiapas”, in Mattiace, Shannan, Aída Hernández, y Jan Rus (editors) 2002. Tierra, Libertady Autonomia: Impactos Regionales del Zapatismo en Chiapas. México: Centro de Investigaciones y Estudios Superiores en Antropología Social, International Work Group for Indigenous Affairs, pp. 83-123.

—, 2002b, "Una nueva idea de nación: autonomía indígena en México”. En Mattiace, Shannan, Aída Hernández, y Jan Rus (eds) 2002. Tierra, Libertady Autonomía: Impactos Regionales del Zapatismo en Chiapas. México: Centro de Investigaciones y Estudios Superiores en Antropología Social, International Work Group for Indigenous Affairs, pp. 229-268.

Nugent, D. y Ana María Alonso, 1994, "Multiple selective traditions in agrarian reform and agrarian struggle: popular culture and state formation in the ejido of Namiquipa, Chihuahua". En Gilbert Joseph y Daniel Nugent. Everyday forms of state formation. Revolution and the negotiation of the rule in modern Mexico. USA, Duke University Press. pp. 209-246. Rivera, Carolina, 2001a, "Expresiones del cristianismo en Chiapas". Revista Pueblos y Fronteras. Núm. 1. Mayo del 2001. México, unAM-PROIMMSE, pp. 67-91.

—, 2001b, "Protestantismo y liberalismo en la frontera oriental de Chiapas". Revista Pueblos y Fronteras. Núm. 2. Noviembre del 2001. México, unAm-Proimmse, pp. 31-45.

- Ma. del Carmen García, Miguel Lisbona e Irene Sánchez, Diversidad religiosa y conflicto en Chiapas. Intereses, utopias y realidades. unAm y Subsecretaría de Asuntos Religiosos. En prensa.

Robledo Hernández Gabriela 1987. Disidencia y religión. Los expulsados de San Juan Chamula. Tesis de licenciatura en Antropología Social, ENAH.

Rus, Jan, 1994, The "Comunidad Revolucionaria Institucional". The subversion of native government in Highland Chiapas, 1936-1968", en Joseph, Gilbert M. y Daniel Nugent (eds.) Everyday Forms of State Formation. Revolution and the Negotiation of Rule in Modern Mexico. Durham, NC and London: Duke University Press. pp 265-300. 
—, y George Collier, 2002, “Una generación en crisis en Los Altos de Chiapas: Los casos de Chamula y Zinacantán, 19742000”, en Mattiace, Shannan, Aída Hernández, y Jan Rus (eds) 2002. Tierra, Libertady Autonomía: Impactos Regionales del Zapatismo en Chiapas. México: Centro de Investigaciones y Estudios Superiores en Antropología Social, International Work Group for Indigenous Affairs, pp. 157-199.

Ruz, Mario H. (edit.), 1983, Los Legítimos Hombres. Aproximación Antropológica al Grupo Tojolabal, México: Universidad Nacional Autónoma de México, 4 Vols.

Sonnleitner, Willibald, 2001, Los Indígenas y la Democratización Electoral. Una Década de Cambio Político entre los Trotziles y Treltales de los Altos de Chiapas (1988-2000). México: El Colegio de México, Instituto Federal Electoral.

Starn, Orin, 1992, "I Dreamed of Foxes and Hawks": Reflections on Peasant Protest, New Social Movements and the Roondas Campesinas of Northern Peru", en Arturo Escobar and Sonia Álvarez (ed). The making of Social Movements in Latin America, Boulder CO: Westview Press.

—, 1997, "Villagers and arms: war and counterrevolution in Peru's Andes", en Fox, Richard G, y Orin Starn. Between Resistance and Revolution. Cultural Politics and Social Protest. Rutgest University Press.
Tejera Gaona, Héctor, 1997, Identidad, Formación Regionaly Conflicto Político en Chiapas. México: Instituto Nacional de Antropología e Historia, Centro de Investigaciones Humanísticas de Mesoamérica. Serie Científica. Antropología 362.

Van Der Haar, Gemma, 2000, "El fin de las fincas comitecas de la zona alta tojolabal: historia de un desenlace", en Anuario, Instituto de Estudios Indígenas, Universidad Autónoma de Chiapas, vII: 105-126

_, 2001, Gaining ground. Land reform and the constitution of community in the Tojolabal highland of Chiapas, México. FLACSO-CLACS, Thela Latin America Series.

Villafuerte, Daniel et al. 1999. La Tierra en Chiapas. Viejos Problemas Nuevos. México: Plaza y Valdés.

Viqueira, Juan Pedro, 2002, Encrucijadas Chiapanecas. México: Tusquest.

—, and Willibald Sonnleitner (eds.) (2000), Democracia en Tierras Indigenas. Las Elecciones en Los Altos de Chiapas (1991-1998). México: El Colegio de México, Instituto Federal Electoral, Centro de Investigaciones y Estudios Superiores en Antropología Social.

Wilson, Richard, 1995, Mayan Resurgence in Guatemala. Q'eqchi' experiences. University of Oklahoma Press.

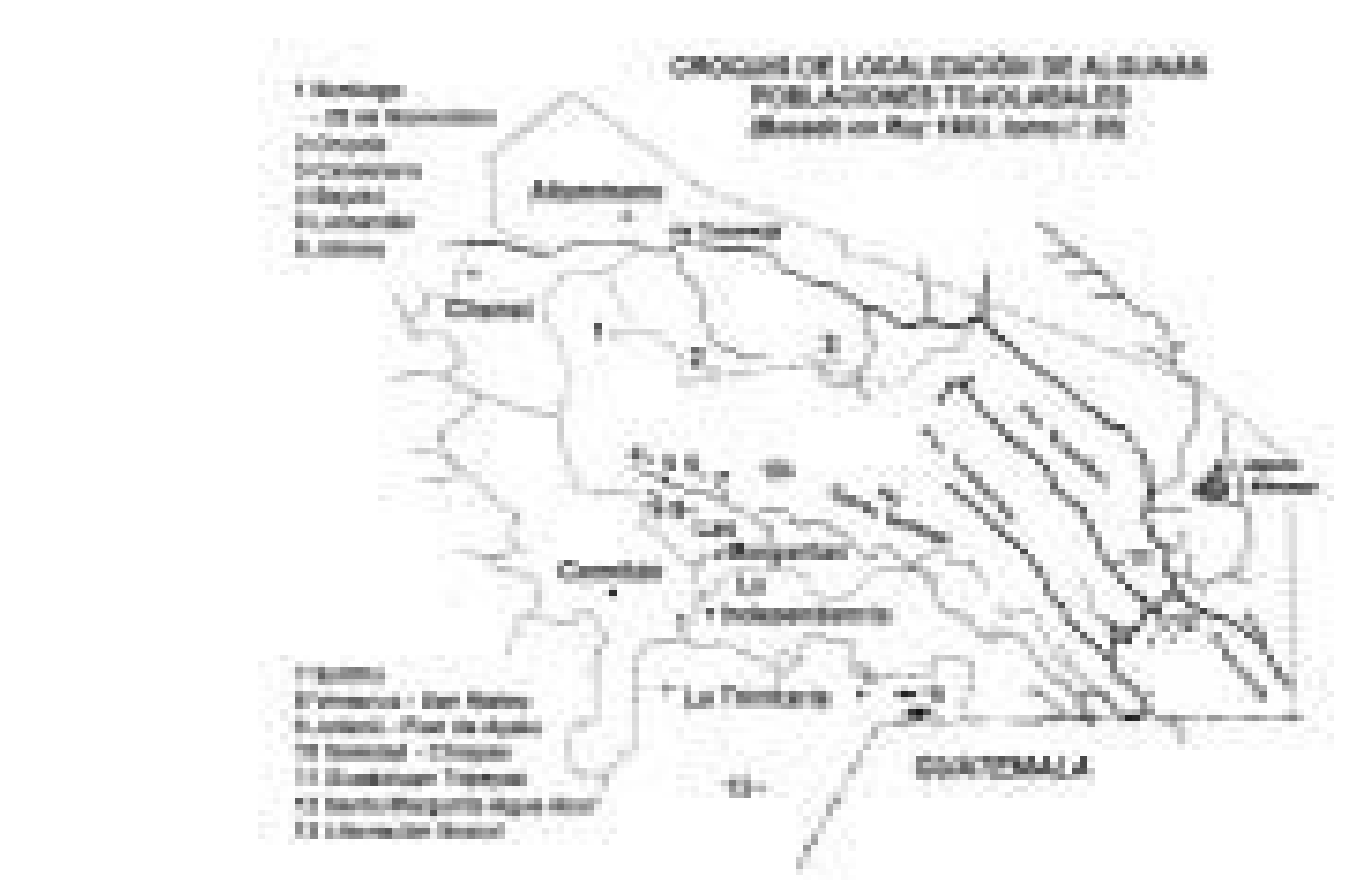

